\title{
Editorial: Social Justice Scholarship in a Neoliberal Governance Context
}

DAVID BUTZ

Editor-in-Chief, Brock University, Canada

The articles that follow constitute the first installment of a special double issue of Studies in Social Justice devoted to the perils and potentialities of combining scholarly work in an academic setting with social justice activism. They are also the first pieces published by the journal since it moved to the Social Justice Research Institute (SJRI) at Brock University. ${ }^{1}$ It is appropriate that the journal's inaugural issues at its new home focus on the simultaneously fraught and productive relationship between activist and academic work, because the circumstances that brought Studies in Social Justice to Brock exemplify some of the challenges, opportunities, and ironies implicit in that relationship.

Studies in Social Justice was launched in 2007 at the University of Windsor, and published its first eight volumes from Windsor's Centre for Studies in Social Justice. In 2013 the Centre was dismantled as part of the University's response to the Government of Ontario's governance agenda for the province's tertiary education sector; an agenda that combines funding cuts with greater provincial oversight, rationalisation of programming, and an emphasis on public-private partnerships as sources of university revenue. Studies in Social Justice was left without funding or an institutional home, a casualty of neoliberal rationalisation. At about the same time - and in response to the same provincial strategy - Brock University created and funded five new transdisciplinary research institutes. One of them, The Social Justice Research Institute (SJRI), assumed management of Studies in Social Justice.

The SJRI's establishment is a welcome development for Brock faculty and students eager to pursue social justice research and activist work in a supportive and well-resourced academic environment. Its programming so far has generated many productive collaborations among scholars and with

\footnotetext{
${ }^{1}$ To learn more about the Social Justice Research Institute (SJRI), or to become a participating member, please visit http://www.brocku.ca/social-justice-research-institute.
} 
community groups, seeded numerous new research projects, supported the social justice-oriented training of graduate students and postdoctoral fellows, and raised the profile of social justice scholarship on campus. We are thrilled that Brock has committed substantial funding to a social justice research institute, if only for a limited period.

At the same time, ensuring that the SJRI operates effectively to nourish radical scholarship or progressive social change is a constant challenge given the current university governance context, which requires universities to satisfy an increasingly broad mandate with relatively fewer resources. In this context, Brock's new institutes will be considered sustainable beyond an initial period of generous university funding only if they become net revenue generators for the university through some combination of (a) direct funding that covers their operating costs (e.g., external grants or 'public-private partnerships'), (b) the trickle-down effects of enhancing Brock's reputation or name-recognition (e.g., increased enrolments or research funding), or (c) serving effectively as flexible resources to meet Brock's rapidly-changing obligations to the provincial government through which it is funded (e.g., transdisciplinary or community collaborations). ${ }^{2}$ The vulnerability and lack of autonomy for SJRI that is implicit in this combination of university expectations is at best a worrying distraction from the job of nurturing frontline social justice research and activist work; at worst, it enrolls the SJRI into the very mechanisms of neoliberal governance that social justice advocates strenuously oppose. The latter is a constant danger - perhaps even an inevitability - because the SJRI is funded directly through the Office of Research Services (rather than through the university's longstanding faculty and departmental governance structure), and therefore may be required to serve strategic or tactical goals that have little to do with the Institute's social justice mandate.

As the articles in these special issues on scholarship and activism stress, the tensions and contradictions I've hinted at are characteristic of - if not inherent in - efforts to pursue a social justice agenda focused on transformative social change from within academic institutions that are heavily invested in succeeding in a competitive university funding environment. Although most of the issues' authors share with the founders of the SJRI a conviction that the opportunities of pursuing scholar-activism in the present neoliberal governance context outweigh the risks, they also recognise the risks and offer their own experientially-informed strategies for managing them. I hope the SJRI is able to learn from their insights.

\footnotetext{
${ }^{2}$ The difficulty in measuring (b) and (c) results in frequent reporting exercises and the nebulous language of 'virtual balance sheets.'
}

Studies in Social Justice, Volume 9, Issue 1, 1-6, 2015 
Readers and authors who have come to appreciate the quality and availability of pieces published in Studies in Social Justice will be relieved to learn that the journal's relocation to the SJRI at Brock University has not resulted in significant changes to its mandate, existing rigorous review and editorial procedures, or open accessibility. The transition has involved adopting the Creative Commons copyright licensing designation BY-ND-NC for the journal's publications, ${ }^{3}$ and adding two new sections - Dispatches and Creative Interventions - designed to expand the journal's interdisciplinary character and stylistic variety. The journal now invites contributions to five sections:

- Research Articles (6,000-8,000 words): original, previously-unpublished, and fully-referenced research contributions that significantly extend knowledge in the broad field of social justice along substantive, theoretical or methodological lines, and which are likely to be of interest to researchers and practitioners. Articles are peer-reviewed by a minimum of two reviewers in a double-blind process.

- Review Essays (< 6,000 words): critical and evaluative overviews of particular literatures, theoretical traditions, debates, activist experiences, etc., relating to social justice. Review essays are intended as expert overviews for the benefit of activists and researchers who are unfamiliar with the area. Review essays are peer-reviewed by a minimum of two reviewers in a double-blind process.

- Book Reviews (1,000-2,000 words): reviews of important theoretical, political and research works relating to social justice issues. Book reviews are vetted by the book review editors, but are not subject to peer review.

- Dispatches $(<4,000$ words): reports or commentaries from the nonacademic and academic spaces of social justice practice, discourse and contestation. Dispatches may report on research activities, methodological innovations, movement experiences, mobilisation efforts, educational practices, social justice events and actions, etc. They need not employ an academic writing style or speaking position. Dispatches are reviewed and vetted by the editorial team, which works with authors as necessary to help shape submissions for publication. They are not exposed to a blind review process.

- Creative Interventions: visual, aural or textual products that reflect on social justice issues using an aesthetic or evocative mode of address. Creative interventions are reviewed and vetted by members of the

\footnotetext{
${ }^{3}$ Copyright for articles published in this journal is retained by their authors, with first publication rights granted to the journal. By virtue of their appearance in this open access journal, articles may be used, with proper attribution (BY), in educational and other non-commercial settings (NC); although articles may be quoted with attribution, they may not be used to create derivative works without authors' permission (ND) - hence the copyright licensing designation BY-NDNC.
} 
editorial team or others with competence in the relevant areas of creative practice. They are not exposed to a blind review process.

The editors welcome independent submissions to each of these sections, as well as proposals for guest-edited issues that include contributions in one or more sections. We also invite submissions that combine or overlap categories, as do the articles in the present issue. These pieces are by design hybrids of research articles and dispatches: dispatches in that they reflect on the authors' personal experiences as scholar-activists in a particular field of social justice practice (i.e., the university), and research articles because they expose these experiences to theoretically-informed analysis, and have passed through a double blind review process.

The journal's expanded disciplinary reach and stylistic variety, together with attrition in editorial personnel associated with its relocation to Brock, has meant assembling a new editorial team, as follows:

- David Butz, PhD (Journal Manager, Editor-in-Chief): I am a professor in the Department of Geography at Brock University, and a founding member of the faculty steering committee of the Social Justice Research Institute. I was for three years director of Brock's interdisciplinary graduate program in Social Justice and Equity Studies. From 2005-2015 I was an editor of ACME: An International E-Journal for Critical Geographies, also an open-access, on-line, peer-reviewed journal, and I have served on the editorial boards of four other journals. My research deals mainly with modernisation, social transformation, and political ecology in mountainous northern Pakistan, with a recent emphasis on road building and mobility justice. I have also done work on the restructuring of the automobile industry in southern Ontario, spatiality in Jamaican reggae music, epistemological and methodological aspects of autoethnography, autobiography and autophotograpy, and the limitations of liberal understandings of research ethics.

- Monique Deveaux, PhD (Editor): Monique is a professor in the Department of Philosophy and Canada Research Chair in Ethics and Global Social Change at the University of Guelph. She serves on the advisory board of Rowman \& Littlefield's book series, 'Studies in Social and Global Justice', and is director of 'Initiatives in Global Justice' at the University of Guelph. Monique's research lies at the intersection of normative ethics and social/political philosophy; it aims to bring social and political theory to bear on real-world problems, such as inequality, poverty, gender and racial injustice, and issues of culturalreligious accommodation. 
- Vanessa Farr, PhD (Dispatches Editor): Vanessa is an independent scholar, writer and consultant based in South Africa. She earned her PhD in Women's Studies from York University, and has extensive field-level experience with crisis prevention and recovery in conflict-affected countries worldwide, especially in Africa and the Middle East. Her areas of specialisation include demobilisation, disarmament and reintegration (DDR), the gendered impacts of small arms and light weapons, social development and gender, early recovery programming in protracted crises, and diverse aspects of women's peacebuilding.

- Julie Gregory, PhD (Book Review Co-Editor): Julie recently graduated from the PhD program in Sociology at Queen's University, where she investigated how various overlapping discourses buttress images of university campuses as particularly (un)safe environments requiring augmented techno-security apparatuses. Her research is concerned with the commodification of fear, risk and security, community-based responses to crime, deviance and justice, and moral panics, social problems and moral regulation. She is also interested in post-subcultural theories and identities.

- Suzan Ilcan, PhD (Editor): Suzan is a professor in the Department of Sociology \& Legal Studies at the University of Waterloo and Balsillie School of International Affairs, and a founding editor of Studies in Social Justice. She serves as a consulting editor of the Canadian Review of Sociology and as an editorial board member of Globalizations and the Journal of Namibian Studies. Suzan's research covers themes at the interface of global governance, humanitarian and development aid, and migration studies, including humanitarian aid and refugees, citizenship rights and social justice, and the politics of poverty and development.

- Caleb Johnston, PhD (Creative Interventions Editor): Caleb is a lecturer in human geography at the University of Edinburgh. He has served as a steering committee member of the Glasgow Refugee, Asylum and Migration Network, as well as the Global Justice Academy at the University of Edinburgh, and currently serves on the editorial board of Environment and Planning D: Society \& Space. Caleb's research has involved substantive ethnographic work in the city of Ahmedabad, India, where he collaborated with two adivasi (indigenous) communities examining a range of issues related to a contemporary subaltern urbanism. He also has a long history working at the intersection of the social sciences and the arts. This work has paid particular attention to the capacity of testimonial theatre to produce sites for popular politics, circulating stories of suffering, and for forging new political attachments. $\mathrm{He}$ is the co-creator of Nanay: A Testimonial Play, a documentary play engendering public debate about Canada's Live-In Caregiver Program, which has been performed in Vancouver, Berlin, Edinburgh, and Manila.

- Samah Sabra, PhD (Book Review Co-Editor): Samah completed an interdisciplinary $\mathrm{PhD}$ at Carleton University. Her ethnographic doctoral 
research examined how Arab Canadians in the Ottawa region negotiated various (pan)national identity discourses in their narratives about their own and others immigration experiences. Samah works as an educational developer at Carleton University, where her main areas of interest are pedagogical practices related to creating inclusive post-secondary educational spaces.

This seven person editorial team is complemented and supported by an international editorial advisory board that presently numbers 17 scholars with a wide range of disciplinary and transdisciplinary competencies in areas of research related to social justice. We plan to expand the breadth of the editorial board over the coming months, so please contact me if you are interested in serving.

The opportunity to guide Studies in Social Justice into a new phase of its existence is at once exciting and daunting. I'm delighted to be accompanied on this venture by six energetic and highly-qualified co-editors, and supported by an equally energetic and accomplished faculty steering committee at the SJRI. I'm also most thankful to the journal's previous editors (Drs. Tanya Basok, Suzan Ilcan and Jeffrey Noonan) and manager (Ms. Nicole Noel) whose hard work and wise decisions over the past eight years have ensured that Studies in Social Justice is solidly established and well-positioned to further increase its readership, visibility and influence. Finally, I wish to acknowledge Sandra Smeltzer and Sara Cantillon, the guest editors of this special double issue, whose cooperation and initiative has greatly helped the journal to enter this new phase of its existence on a strong footing. 